\title{
Antiulcer Activity of Morinda Citrifolia Linn Fruit Extract
}

\author{
P. Muralidharan ${ }^{1}$ and J. Srikanth \\ Department of Pharmacology and Toxicology, C.L.Baid Metha College of Pharmacy, Jyothi Nagar, \\ Thoraippakkam, Chennai-600 097, Tamilnadu, India
}

Received 20 November 2008, accepted in final revised form 24 February 2009

\begin{abstract}
The study was designed to investigate the antiulcer activity of ethyl acetate extract of the fruits of Morinda citrifolia Linn (Rubiaceae) using different models of gastric and duodenal ulceration in rats. Gastric ulcers were induced by oral administration of ethanol, aspirin and by pyloric ligation and duodenal ulcers were induced by oral administration of cysteamine $\mathrm{HCl}$. The extract was administered at a dose of 200 and $400 \mathrm{mg} / \mathrm{kg}$ orally $30 \mathrm{~min}$ prior to ulcer induction. Ranitidine $(50 \mathrm{mg} / \mathrm{kg})$ was used as a reference standard. The antiulcer activity was accessed by determining and comparing the ulcer index in the test group with that of the standard drug treated group. Gastric volume, total acid and free acid were estimated in the pylorus-ligated rats. M.citrifolia $(400 \mathrm{mg} / \mathrm{kg}$ ) showed maximum inhibition of gastric acid, free acid and total acid to $53.54 \%, 52.55 \%$ and $30.30 \%$, respectively. The ulcer index in the M.citrifolia treated animals was found to be significantly less in all the models compared to standard drug treated cases. The antiulcer activity of M.citrifolia was, however, less than that of ranitidine. The results suggest that M.citrifolia possesses significant antiulcer property which could be due to cytoprotective action of the drug or strengthening of gastric and duodenal mucosa with the enhancement of mucosal defence.
\end{abstract}

Keywords: Morinda citrifolia; Antiulcer.

(C) 2009 JSR Publications. ISSN: 2070-0237 (Print); 2070-0245 (Online). All rights reserved.

DOI: $10.3329 /$ jsr.v1i2.1625

\section{Introduction}

Man has used plants as medicines for thousands of years [1]. Traditionally peptic ulcers have been described as an imbalance between the luminal acid peptic attack versus the mucosal defense [2]. The treatment of peptic ulcers with plant products used in folk medicine and the protection of induced gastric ulcer in laboratory animals using medicinal plants was reported [3]. Generally plant flavonoids have been found to be effective against ulcer in experimental animals [4] and exhibit several biological effects [5]. The present study has, therefore, been conducted to evaluate the antiulcer activity of ethyl acetate

\footnotetext{
${ }^{1}$ Corresponding author: pmuralidaran2008@rediffmail.com
} 
extract of Morinda citrifolia fruit using ulcer models in rats since this extract has potent anti oxidant activity as previously reported.

Morinda citrifolia Linn Rubiaceae known commercially as Noni grows widely throughout the Pacific and is one of the most significant sources of traditional medicines among Pacific island societies. The Noni plant is used in combinations for herbal remedies. The fruit juice is in high demand in medicine for different kinds of illnesses such as arthritis, diabetes, high blood pressure, muscle aches and pains, gastric ulcers, menstrual difficulties, headaches, heart disease, AIDS, cancers, gastric ulcers, sprains, mental depression, senility, poor digestion, atherosclerosis, blood vessel problem, and drug addiction [6].

A number of major components has been identified in the Noni plant such as octoanoic acid, potassium, vitamin c,scopoletin,terpenoids, alkaloids, anthraquinones (such as nordamnacanthal, morindone, rubiadin, rubiadia-1-methyl ether, antraquinone glycosides) $\beta$-sitosterol, carotene, vitamin A, flavone glycosides, linoleic acid, alizarin, amino acids, acubin, 1-asperuloside, caproic acid, caprylic acid, ursolic acid, rutin and putative proxeronine[7]. Antitumor activity expressed in enhanced survival of tumorbearing mice has been demonstrated after treating with juice extracts [8, 9]. Aqueous extracts of roots were shown to have an analgesic effect on mice without any sign of toxicity and a sedative effect at high doses [10].

The Morinda citrifolia fruit has been claimed to have antiulcer activity [6], but no detailed scientific investigations have been carried out to define the antiulcer activities of Morinda citrifolia. Thus the present investigation sets out to study the antiulcer activity of Morinda citrifolia fruit extract. The effect produced by Morinda citrifolia was compared with that of ranitidine, a standard drug.

\section{Materials and Methods}

\subsection{Plant material}

Morinda citrifolia fruits were collected from Abhirami Botanicals, Tuticorin, Tamilnadu. The plant was identified and authenticated by Dr. Sasikala Ethirajulu, Research Officer (Pharmacognosy), Central Research Institute for Siddha, Chennai, India. A voucher specimen was deposited in our laboratory for future reference.

\subsection{Preparation of extract}

The samples were washed with running tap water and separated before being chopped into pieces. They were oven-dried at $45^{\circ} \mathrm{C}$ for 2 days and ground to powder. The ground powder was extracted with methanol in a water bath at room temperature for $24 \mathrm{~h}$. The solvent was then removed by filtration and fresh solvent was then added to the plant material. The extraction process was twice repeated. The combined filtrates were then evaporated under reduced pressure to give a dark green viscous mass. This methanol 
crude extract was further extracted with ethyl acetate and water, and then separated using separating funnels. These ethyl acetate-soluble fractions were later evaporated and afforded the ethyl acetate extract [11]. The extract was stored at $0-4{ }^{\circ} \mathrm{C}$. The percentage yield was $16 \% \mathrm{w} / \mathrm{w}$. This extract was used for animal administration.

\subsection{Experimental animals}

Inbred colony strains of Wistar rats of either sex weighing 150-250 g procured from the animal house of C. L. Baid Metha College of Pharmacy were used for the study. The animals were maintained in polypropylene cages of standard dimensions at a temperature of $28 \pm 1{ }^{\circ} \mathrm{C}$ and standard 12 hour: 12 hour day/night rhythm. The animals were fed with standard rodent pellet diet (Hindustan Lever Ltd.) and water ad libitum. Prior to the experiment, the animals were acclimatized to the laboratory conditions. The experimental protocol was approved by Institutional Animal Ethical Committee (IAEC) constituted under CPCSEA. IAEC ref no: IAEC/XII/06/CLBMCP/2007-2008 dated 20-04-2007.

\subsection{Preliminary phytochemical analysis}

The ethyl acetate extract of the fruit of Morinda citrifolia Linn was subjected to preliminary phytochemical screening [12].

\subsection{Acute toxicity studies}

Albino mice weighing 22-25 g selected by random sampling technique were used in the study. Acute oral toxicity was performed as per OECD- 423 guidelines [13]. The animals were fasted overnight, provided only water after which extract was administered to the groups orally at the dose level of $5 \mathrm{mg} / \mathrm{kg}$ body weight by gastric intubation and the groups were observed for 14 days. If mortality was observed in 2 or 3 animals among 6 animals then the dose administered was assigned as a toxic dose. If mortality was observed in one animal, then the same dose was repeated again to confirm the toxic dose. If mortality was not observed, the procedure was repeated for further higher doses such as 50,300 and 2,000 mg/ kg body weight. The animals were observed for toxic symptoms such as behavioral changes, locomotion, convulsions and mortality for 72 hours.

\subsection{Aspirin-induced gastric lesions}

Aspirin ( $0.2 \mathrm{~g} / \mathrm{kg} \mathrm{x} 3$ days) were administered once per day to groups of animals for the number of days specified [14]. Animals of control group received 1\% carboxy methyl cellulose (CMC) suspension and test groups received M.citrifolia suspension orally at two dose levels (200 and $400 \mathrm{mg} / \mathrm{kg}$ ) for 10 days. From day 8 the animals received CMC/ M.citrifolia two hours prior to the administration of aspirin. Overnight fasted animals 
were sacrificed by cervical dislocation one hour after the last dose of ulcerogen. The stomach was incised along the greater curvature and examined for ulcers.

\subsection{Alcohol-induced gastric lesions}

Groups of rats fasted for $24 \mathrm{~h}$ received either M.citrifolia (200 and 400mg/kg) or control vehicle. After $30 \mathrm{~min}$, ulceration was induced by oral administration of $50 \%$ ethanol (5 $\mathrm{ml} / \mathrm{kg}$ ). The animals were sacrificed after $1 \mathrm{~h}$ following administration of ethanol [15]. The stomach was removed, opened along the greater curvature and sum of length of lesions $(\mathrm{mm})$ was calculated and expressed as lesion index.

\subsection{Pylorus ligated rats}

M.citrifolia (200 and $400 \mathrm{mg} / \mathrm{kg}$ ) was administered for a period of 7 days. On day 7, after the last dose of M.citrifolia, the rats were kept for 24 hours fasting and care was taken to avoid coprophagy. Under light ether anesthesia, the abdomen was opened and pylorus was ligated without causing any damage to its blood vessels. The stomach was replaced carefully and the abdominal wall was closed with interrupted sutures. The animals were deprived of water during the postoperative period [16]. Four hours after ligation, stomachs were dissected out and contents were collected into clean tubes. Volume, $\mathrm{pH}$, free acid and total acid content of gastric juice were determined. The contents were centrifuged, filtered and subjected to titration for estimation of free and total acidity. $1 \mathrm{ml}$ of centrifuged and filtered gastric secretion was titrated against $0.1 \mathrm{~N}$ Sodium hydroxide using Topfers reagent as indicator for determination of free acidity and $1 \%$ phenolphthalein as indicator for combined acidity. The sum of the two titrations was total acidity [17]. The stomach was opened along the greater curvature and examined for ulcers. The ulcer index was evaluated using the method described earlier [18].

\subsection{Cysteamine $\mathrm{HCl}$ induced duodenal ulcers}

Rats were treated with M.citrifolia (200\& $400 \mathrm{mg} / \mathrm{kg}$ ) orally for a period of 7 days. On day 8 , the overnight fasted animals were given a single subcutaneous injection of cysteamine hydrochloride $(30 \mathrm{mg} / \mathrm{kg}$ ) and the animals were killed by cervical dislocation after 18 hours [19] duodenum was examined for the presence or absence of ulcers.

\subsection{Statistical analysis}

Statistical analysis was carried out by using ANOVA followed by Dunnet's multiple comparison tests using Graph pad PRISM software version 4.03 (2005). ' $P$ ' values $<0.05$ were considered significant. 


\section{Results}

The preliminary phytochemical screening carried out on ethyl acetate extract of M.citrifolia revealed the presence of phytoconstituents such as alkaloids, flavanoids, carbohydrates, glycosides, phenols, gums and mucilage. (Table 1)

Table 1. Preliminary phytochemical test of M.citrifolia fruit ethyl acetate extract.

\begin{tabular}{clc}
\hline Sl. No & Phytochemical Tests & Results \\
\hline 1. & Test for Alkaloids & + \\
2. & Test for Carbohydrates & + \\
3. & Test for Proteins & + \\
4. & Test for Steroids & - \\
5. & Test for Sterols & - \\
6. & Test for Phenols & + \\
7. & Test for Flavanoids & + \\
8. & Test for Gums and mucilage & + \\
9. & Test for Glycosides & + \\
10. & Test for Saponins & - \\
11. & Test for Terpenes & - \\
\hline + Indicates the presence of compounds. & \\
- Indicates the absence of compounds. &
\end{tabular}

The extract did not produce any toxic symptoms of mortality up to the dose level of $2000 \mathrm{mg} / \mathrm{kg}$ body weight in rats, and hence the drugs were considered safe for further pharmacological screening. According to the OECD-423 guidelines for acute oral toxicity, the LD50 dose of $2000 \mathrm{mg} / \mathrm{kg}$ and above is categorized as unclassified.

During the course of the study, the incidence and severity of aspirin and alcohol induced ulcerations were significantly reduced by M.citrifolia. Induction of duodenal ulcers in rats with cysteamine hydrochloride showed the presence of ulcers in all the animals in the control group, which was significantly reduced in the M.citrifolia treated group. The values are shown in Table 2 .

Table 2. Anti ulcer activity of the Morinda citrifolia fruit ethyl acetate extract.

\begin{tabular}{clccc}
\hline \multirow{2}{*}{$\begin{array}{c}\text { Ulcerogen } \\
\text { and } \\
\text { Dose }\end{array}$} & Control & $\begin{array}{c}\text { M.citrifolia } \\
(200 \mathrm{mg} / \mathrm{kg})\end{array}$ & $\begin{array}{c}\text { M.citrifolia } \\
(400 \mathrm{mg} / \mathrm{kg})\end{array}$ & $\begin{array}{l}\text { Ranitidine } \\
(50 \mathrm{mg} / \mathrm{kg})\end{array}$ \\
\hline $\begin{array}{c}\text { Aspirin } \\
(200 \mathrm{mg} / \mathrm{kg})\end{array}$ & $25.00 \pm 0.37$ & $18.38 \pm 0.22^{*}$ & $13.44 \pm 0.37^{*}$ & $8.48 \pm 0.11^{*}$ \\
$\begin{array}{c}\text { Alcohol } \\
(80 \%)\end{array}$ & $36.76 \pm 0.33$ & $23.24 \pm 0.36^{*}$ & $22.06 \pm 0.31^{*}$ & $16.25 \pm 0.17^{*}$ \\
$\begin{array}{c}\text { Cysteamine } \mathrm{HCl} \\
(30 \mathrm{mg} / \mathrm{kg})\end{array}$ & $32.30 \pm 0.46$ & $19.66 \pm 0.29^{*}$ & $15.66 \pm 0.28^{*}$ & $13.54 \pm 0.32^{*}$ \\
\hline
\end{tabular}

Values are mean \pm SE of 8 animals in each group $(n=8)$; ${ }^{*} P<0.05$ compared with respective control group.

Effect of M.citrifolia on gastric volume, free acid, total acid and ulcer in pylorus ligated rats were studied. M.citrifolia (200 and $400 \mathrm{mg} / \mathrm{kg}$ ) inhibited the volume of gastric 
juice secreted by the control rats by $21.559 \%$ and $53.54 \%$, respectively. The free acid and the total acid were reduced by the extract to $39.03,17.77 \%$ and $52.55,30.30 \%$, respectively for the 200 and $400 \mathrm{mg} / \mathrm{kg}$. M.citrifolia administered in doses 200 and 400 $\mathrm{mg} / \mathrm{kg}$ orally cause a dose dependent decrease in ulcer index in pylorus ligated rats. The dose of $400 \mathrm{mg} / \mathrm{kg}$ showed maximum ulcer protection of $55.6 \%$. The values are shown in Table 3 .

Table 3. Effect of Morinda citrifolia fruit ethyl acetate extract on gastric volume, free acid, total acid and ulcer index in pylorus ligated rats.

\begin{tabular}{lccccc}
\hline \multirow{2}{*}{ Parameters } & Control & $\begin{array}{c}\text { M.citrifolia } \\
(200 \mathrm{mg} / \mathrm{kg})\end{array}$ & $\begin{array}{l}\text { Percentage } \\
\text { inhibition }\end{array}$ & $\begin{array}{c}\text { M.citrifolia } \\
(400 \mathrm{mg} / \mathrm{kg})\end{array}$ & $\begin{array}{l}\text { Percentage } \\
\text { inhibition }\end{array}$ \\
\cline { 2 - 6 } & $7.64 \pm 0.33$ & $5.99 \pm 0.37^{*}$ & 21.59 & $3.55 \pm 0.13$ & 53.54 \\
\hline $\begin{array}{c}\text { Gastric volume } \\
(\mathrm{ml} / 100 \mathrm{~g})\end{array}$ & $392.0 \pm 4.5$ & $239.11 \pm 2.06^{*}$ & 39.03 & $186 \pm 1.88^{*}$ & 52.55 \\
$\begin{array}{c}\text { Free acid } \\
(\mu \mathrm{Eq} / 100 \mathrm{~g} / 4 \mathrm{~h})\end{array}$ & $489.29 \pm 3.35$ & $402.33 \pm 2.46^{*}$ & 17.77 & $341.11 \pm 2.60^{*}$ & 30.30 \\
$\begin{array}{c}\text { Total acid } \\
(\mu \mathrm{Eq} / 100 \mathrm{~g} / 4 \mathrm{~h})\end{array}$ & $27.28 \pm 0.69$ & $22.88 \pm 0.42^{*}$ & 16.13 & $17.99 \pm 0.80^{*}$ & 34.05 \\
\hline Ulcer Index & & &
\end{tabular}

Values are mean \pm SE of 8 animals in each group; ${ }^{*} P<0.05$ compared with respective control group.

\section{Discussion and Conclusion}

In most of the cases the etiology of the ulcer is unknown. It is generally accepted that it results from an imbalance between aggressive factors and the maintenance of the mucosal integrity through the endogenous defense mechanism [20]. To regain the balance, different therapeutic agents including plant extracts are used to inhibit the gastric acid secretion or to encourage the mucosal defense mechanisms by increasing mucus production, stabilizing the surface epithelial cells, or interfering with the prostaglandin synthesis.

Even though many products in the market for the treatment of gastric ulcers, including antacids, proton pump inhibitors, anticholinergics and histamine $\mathrm{H} 2$-antagonists, are used, most of these drugs produce several adverse reactions, such as gynecomastia, hematopoietic changes, acute interstitial nephritis [21], thrombocytopenia [22], anaphylaxis reactions [23], nephrotoxicity and hepatotoxicity [24]. Medicinal plants are amongst the most attractive sources of new drugs, and have been shown to give promising results in treatment of gastric and duodenal ulcers.

The anti ulcerogenic activity of $M$. citrifolia was evaluated by employing aspirin and alcohol induced ulcerations in rats. Non-steroidal anti-inflammatory drugs (NSAIDs) like aspirin are known to induce gastric ulceration. The reason being attributed principally to inhibition of biosynthesis of 'cytoprotective prostaglandins' (by inhibition of cyclooxygenase pathway of arachidonic acid metabolism), resulting in overproduction of leukotrienes and other products of 5-lipoxygenase pathway [25]. Hence, the protective action of M. citrifolia against aspirin- induced gastric lesions could possibly be due to its 5-lipoxygenase inhibitory effect. 
Ethanol-induced gastric lesion formation may be due to stasis in gastric blood flow, which contributes to the development of the haemorrhage and necrotic aspects of tissue injury [26]. It has also been reported that leukotrienes antagonist and 5-lipoxygenase inhibitors are capable of inhibiting alcohol and NSAIDs-induced gastric ulceration in rats [27]. Therefore the protection afforded by the M. citrifolia against alcohol and Aspirininduced gastric ulceration could also be due to inhibition of 5-lipoxygenase pathway or to leukotriene's antagonistic activity.

As the defense potential of mucus perimeter of gastric mucosa depends upon a delicate balance between the processes affecting the synthesis and secretion of its mucin constituents. The effect of $M$. citrifolia on gastric volume, free acid and total acid was evaluated in pyloric-ligated rats. $M$. citrifolia prevented the mucosal lesions induced by aspirin/alcohol. The primary therapeutic approach of an antiulcer agent involves maintenance of a delicate balance of factors controlling the synthesis, secretion and breakdown of its proteins, glycoproteins, and lipid components, so as to strengthen the mucosal integrity [28].

In the present study $M$. citrifolia showed prevention of gastric lesions in the experimental models. M.citrifolia was found to increase the mucous and decrease the acid volume, free and total acid contents in rats. M. citrifolia treatment affects the parameters that influence the initiation and perpetuation of ulceration. In addition, there is extensive experimental evidence, which indicates that certain substances through free radical scavenging protect the gastric mucosa [29].

\section{References}

1. I. B. Suffredini, E. M. Bacchia, and J. A. A. A. Sertie, J. Ethnopharmacol. 65, 217 (1999). doi:10.1016/S0378-8741(98)00211-6

2. S. K. Mutra, S. Gopumadhavan, T. S. Hemavathi, T. S. Muralidhar, and M. V. Venkataranganna, J. Ethnopharmacol. 52,165 (1996). doi:10.1016/0378-8741(95)01414-4

3. Ahmad M. Disi, Salah O. Tamimi, and Ghaleb M. Abuereish, J Ethnopharmacol. 60, 189 (1998). doi:10.1016/S0378-8741(97)00134-7

4. David A. Lewis, William N. Fields and Graham P. Shaw, J Ethnopharmacol. 65, 283 (1999). doi:10.1016/S0378-8741(99)00005-7

5. K. Rajnarayana, M. Sripal Reddy, M. R. Chaluvadi, and D. R. Krishna, Indian J. Pharmacol. 33, $2(2001)$.

6. M-Y. Wang, B. J. West, C.J. Jensen, D. Nowicki, C. X. Su, A. K. Palu , and G. Anderson, Acta pharmcologica sinica 23 (12), 1127 (2002).

7. P. Rastogi and B.N. Mehrotra, Compendium of Indian medicinal plants; Vol. 1 (PID, New Delhi, 1990) p. 279.

8. A. Hirazumi, E. Furrasawa, S. C. Chou, and Y. Hokama, Proc.West Pharmacol Soc. 37, 145 (1994).

9. A. Hirazumi and E. Feurasawa, Phytotherapy Res. 13, 380 (1999). doi:10.1002/(SICI)1099-1573(199908/09)13:5<380::AID-PTR463>3.0.CO;2-M

10. C. Youonos, A. Rolland, J. Fluerentin, M. Lanhers, R. Missilin, and F. Mortier, Planta Medica 56, 430 (1990). doi:10.1055/s-2006-961004

11. Z. Mohd Zin, A. Abdul-Hamid, and A. Osman, Food Chemistry 78, 227 (2002). doi:10.1016/S0308-8146(01)00402-2 


\section{Antiulcer Activity}

12. J. B. Harborne, Phytochemical methods, 2nd edition (Chapman and Hall Publishers, London 1984) p. 50.

13. D. J. Ecobichon, The Basis of Toxicity Testing, 3rd Edition (CRC Press, New York, 1997) pp. 43-86.

14. R. K. Goel, S. Gupta, R. Shankar, and A. K. Sanyal, J Ethnopharmacol. 18, 33 (1986). doi:10.1016/0378-8741(86)90041-3

15. A. Robert, J. E. Nezamis, C. Lancaster, and A. J. Hanchar, Gastroenterology 77, 433 (1979).

16. H. Shay, S. A. Komarov, S. S. Fels, D. Meranze, M. Gruenstein, and H. Siplet, Gastroenterology 5, 43 (1945).

17. N. S. Parmar, G. Hennings and O. P. Gulati, Agents and Actions 15, 143 (1984). doi:10.1007/BF01972340

18. M. L. O. Souza-Formigoni, M. O. M. Oliveira, M. U. Monteiro, N. O. Sileira-Filho, S. Braz, and E. A. Carlini, J. Ethnopharmacol. 34, 21 (1991). doi:10.1016/0378-8741(91)90185-G

19. L. E. Borella, K. Seethaler, and W.Lipmann, Arzneim-Forsch 29, 793 (1979).

20. D. W. Piper and D. D. Stiel, Med. Prog 2, 7 (1986).

21. A. Ra and S. W. Tobe, Annals of Pharmacotherapy 38, 41 (2004). doi:10.1345/aph.1D085

22. J. A. Zlabek and C. G. Anderson, Annals of Pharmacotherapy 36, 809 (2002). doi:10.1345/aph.1A303

23. P. Gonzalez, V. Soriano, P. Lopez and E. Niveiro, Allergie Immunopathology 30, 342 (2002).

24. A. A. Fisher and D. G. Le Couteur, Drug Safety 24, 39 (2001). doi:10.2165/00002018-200124010-00004

25. K. D. Rainsford, Agents and Actions 21, 316 (1987). doi:10.1007/BF01966502

26. P. H. Guth, G. Paulsen, and H. Nagata, Gastroenterology 87, 1083 (1984).

27. M. J. Parnham and K. Brune, Agents and Actions 21, 232 (1987). doi:10.1007/BF01966475

28. G. G. Brown. An introduction to Histotechnology, 1st edition. (Appleton century Crofts, New York. 1978) pp 293 -308.

29. G. B. Glavin and S. Szabo, FASEB.J 6, 821 (1992). 